\title{
Estudio de la eficacia de la aplicación de hidrofugantes para impedir la entrada de agua de lluvia en muros de ladrillo de tejar por albardillas y remates
}

\author{
Analysis of the use of waterproofing treatments on copings and cornices \\ in preservation of the brickwork heritage
}

$\underline{\text { M. S. Camino Olea }}^{(*)}$, F. J. León Vallejo ${ }^{(*)}$, A. Llorente Álvarez ${ }^{(*)}$, J. M. Olivar Parra $^{(*)}$

RESUMEN

En los edificios históricos construidos con ladrillos de tejar es muy frecuente que los muros y las cornisas estén rematados con el mismo ladrillo, sentado a soga o a tizón, con el que está ejecutada la fachada y que estos ladrillos estén más deteriorados que el resto. La causa del deterioro es la acción del agua combinada con la suciedad, la vegetación y otras lesiones relacionadas con la humedad. Uno de los posibles sistemas para conservar y proteger estos elementos es proyectar un hidrofugante. En este artículo se van a exponer los resultados de los ensayos realizados en laboratorio a probetas formadas por muretes de ladrillos, rematados en la parte superior por una albardilla formada por una hilada inclinada, también de ladrillo, con la aplicación de un tratamiento hidrofugante o sin él.

Palabras clave: ladrillo; absorción; succión; hidrofugante; conservación.

\section{ABSTRACT}

In the historic buildings built with face brick tile it is very common to have copings and cornices of soldier or header course, made with the same brick as the facade and these bricks are usually more deteriorated than the rest of the facade. The cause of the deterioration is the action of the water combined with dirt, vegetation, and other moisture-related causes. One of the possible systems to conserve and protect these elements is by projecting a water repellent. This article will present the results of tests conducted on laboratory specimens formed by low brick walls with and without the application of a waterproofing treatment, finished off at the top part by a sloping course also of brick.

Keywords: brick; absorption; suction; waterproofing; conservation.

(*) Universidad de Valladolid (Valladolid, España).

Persona de contacto/Corresponding author: mcamino@arq.uva.es (M. S. Camino Olea)

ORCID: http://orcid.org/oooo-0oo1-5711-3143 (M. S. Camino Olea); http://orcid.org/oooo-00o2-3578-7267

(F. J. León Vallejo); http://orcid.org/oooo-0002-5956-5466 (A. Llorente Álvarez);

http://orcid.org/oooo-0003-4677-993X (J. M. Olivar Parra)

Cómo citar este artículo/Citation: Camino Olea, M. S., León Vallejo, F. J., Llorente Álvarez, A., Olivar Parra, J. M. (2016). Estudio de la eficacia de la aplicación de hidrofugantes para impedir la entrada de agua de lluvia en muros de ladrillo de tejar por albardillas y remates. Informes de la Construcción, 69(545): e184, doi: http://dx.doi.org/10.3989/ic.15.066.

Copyright: (C) 2017 CSIC. Licencia / License: Salvo indicación contraria, todos los contenidos de la edición electrónica de Informes de la Construcción se distribuyen bajo una licencia de uso y distribución Creative Commons Attribution License (CC BY) Spain 3.o. 


\section{INTRODUCCIÓN}

El ladrillo macizo de tejar, con el que están ejecutados los edificios antiguos, es una pieza cerámica respecto de la cual la normativa (1) señala que debería emplearse solamente en fábricas revestidas, protegidas al exterior, porque es un material con una porosidad elevada que puede llegar a absorber agua de lluvia en cantidad importante, así como la argamasa de cal y arena con la que se ejecutan dichas fábricas.

La entrada de agua es el origen de diversas lesiones que deterioran las fábricas, por este motivo la mayor parte de las fachadas ejecutadas con este ladrillo suelen estar revestidas, aunque son numerosos los ejemplos en los que la fábrica se deja vista en toda la fachada o, al menos, en zonas de la misma en las que el ladrillo se ha empleado como elemento ornamental, como en cornisas, recercados de los huecos y remates.

Las hiladas inclinadas que protegen la coronación de los muros y los planos superiores de las cornisas son las zonas más expuestas al agua de lluvia junto con los alféizares. Son las zonas por donde puede penetrar más fácilmente y es donde el ladrillo presenta una mayor degradación debida al depósito de suciedad y crecimiento de vegetación, así como a los ciclos de hielo y deshielo. En la Figura 1 se puede ver en la fotografía de la izquierda, una albardilla formada por una hilada inclinada de ladrillos donde crecen musgos y líquenes y en la fotografía de la derecha en algunos de los ladrillos del remate de la cornisa también hay musgo y se han desprendido trozos de ladrillos.

Cada vez es más común el empleo de hidrofugantes para evitar que el agua de la lluvia penetre en las fábricas actuales, así como el empleo de ladrillos hidrofugados, y empieza a ser un tratamiento que también se realiza en las fábricas antiguas de ladrillo (2).

Para verificar el comportamiento de los hidrofugantes como barrera para impedir el paso del agua por los remates de cornisas y albardillas de muro se han realizado diversos ensayos, en laboratorio, con probetas de muretes rematados por hiladas inclinadas de ladrillo que tratan de imitar los remates de los edificios antiguos.
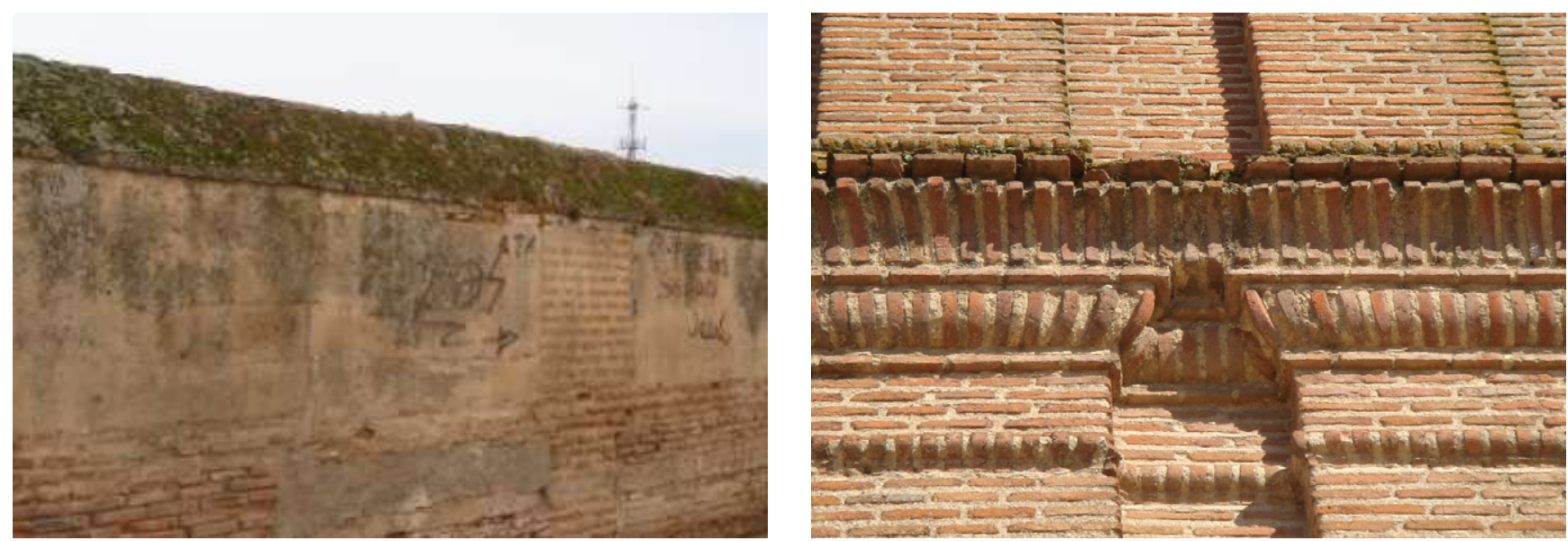

Figura 1. A la izquierda remate de una tapia con hiladas inclinadas, a la derecha cornisa de ladrillos vegetación y donde se han desprendido varias piezas.

\section{METODOLOGÍA Y RESULTADOS}

Para desarrollar la investigación se han localizado ladrillos de tejar procedentes de derribos y se han adquirido ladrillos macizos modernos que imitan el acabado de los ladrillos de tejar, aunque están fabricados por extrusión (Figura 2) y se ha preparado argamasa con arena de río lavada e hidróxido de cal. Se ha realizado el ensayo con dos tipos de ladrillos macizos de

- El ladrillo de tejar se ha localizado en la provincia de Valladolid y lleva grabado en una de las tablas LA OPERARIA. Posiblemente la denominación de la cerámica que fabricaba estos ladrillos, de dimensiones 279, 139, $50 \mathrm{~mm}$, según las especificaciones de la norma UNE-EN 771 (3).

- El ladrillo macizo fabricado por extrusión es de Nava de la Asunción imitando el ladrillo de tejar de la zona, de dimensiones 232, 110, $30 \mathrm{~mm}$, según las especificaciones de la norma UNE-EN 771.

Con estos materiales se han ejecutado los cuatro muretes que se van a ensayar, que están formados por fábricas de tres tizones de anchura y seis hiladas de altura rematadas por una hilada inclinada: dos con ladrillo de tejar antiguo recuperado y dos con ladrillo macizo moderno, los cuatro con argamasa de cal y arena en la proporción 1/3. En dos de las probetas, de siloxanos, del que el fabricante señala que reduce la absorción de agua por capilaridad por tensión superficial y que no actúa como barrera de vapor. Las otras dos se dejaron sin hidrofugar, de esta forma se podía comprobar si había diferencia entre los muretes hidrofugados y los no hidrofugados.

Se ha utilizado este producto porque en ensayos realizados anteriormente se ha comprobado su eficacia sin que se produzcan alteraciones en los materiales hidrofugados, aunque otros autores estiman que para hidrofugar ladrillos son mejores otros tipos de hidrofugantes (4).

Hay diversos estudios en los que se ha experimentado sobre la absorción de agua en materiales compuestos, formados por capas de dos materiales, en los que se ha llegado a la conclusión que cuando los dos materiales presentan valores de absorción muy diferentes, el valor significativo para evaluar la absorción es la del material que menos absorbe (5). En este características diferentes para poder comparar los resultados. una de cada tipo de ladrillo, se aplicó un hidrofugante a base 


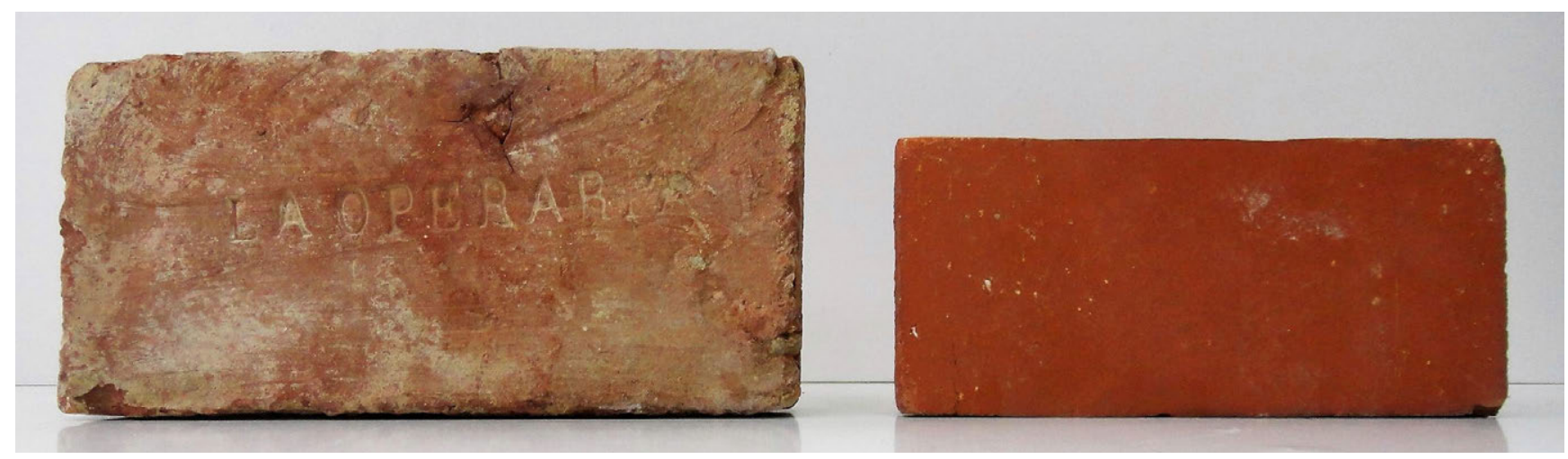

Figura 2. A la izquierda fotografía de un ladrillo de tejar y a la derecha fotografía de un ladrillo macizo moderno, empleados para realizar los ensayos.

caso los dos materiales serían: la hilada de ladrillos y el tendel de argamasa. Para comprobar si sucede lo mismo en estas fábricas de ladrillo se van a realizar ensayos a los ladrillos y a probetas de argamasa según diversas normas UNE-EN de ensayo. Estos ensayos también se realizan con el objetivo de verificar cuál de ellos permite predecir mejor el comportamiento de la fábrica de ladrillo frente a la absorción del agua de lluvia, porque, como ya se ha señalado anteriormente, la entrada de agua se produce por capilaridad debido a la tensión superficial.

\subsection{Ensayos realizados a los muretes con albardilla}

Una vez construidas las cuatro probetas de ladrillo, con aparejo de tizones y gruesas juntas de argamasa, de manera similar a como se ejecutaban las fábricas antiguas, se esperó a que fraguara la argamasa y la fábrica hubiera perdido la humedad de obra, y se aplicó el producto hidrofugante, siguiendo las instrucciones del fabricante, se dieron dos manos con o,50 litros $/ \mathrm{m}^{2}$ por mano (Figura 3).

Para estudiar la absorción se proyectó agua sobre las probetas, una a una, y para controlar la proyección se flanquearon las probetas con planchas de policarbonato y por la parte posterior se situó otra plancha para evitar que el agua humedeciese el trasdós del murete, de esta forma se confinaba la probeta en una caja que solamente estaba abierta por el lado desde el que se proyectaba el agua. Se sellaron las juntas de unión entre los materiales para que no pudiera penetrar el agua por las mismas: las juntas entre las planchas de policarbonato y las juntas entre la fábrica y las planchas (Figura 3).

Las probetas se han ejecutado sobre unos perfiles de acero galvanizado, para impedir que la humedad pudiera ascender por capilaridad, colocadas sobre una balsa hecha con tableros y una lámina impermeable, sobre en el suelo del laboratorio (Figura 3).

El sistema de proyectar agua sobre las probetas se ha definido teniendo en cuenta la norma UNE-EN 13501 «Fachadas ligeras. Estanquidad al agua. Ensayo in situ». En esta norma se emplea una barra con boquillas separadas $400 \mathrm{~mm}$ entre centros y provista de soportes que permitan mantener la colocación de las mismas en una posición correcta. Un dispositivo que permita proyectar sobre la cara externa una película constante y continua y un dispositivo para medir el caudal de agua. Para el ensayo se colocan las boquillas de forma que estén a $250 \mathrm{~mm}$ de la fachada y se regula el caudal constante para proyectar $5 \mathrm{l} / \mathrm{min}$ por metro de barra durante $30 \mathrm{minu}-$ tos. Siguiendo este modelo, para arrojar agua se situó delante de cada probeta una barra vertical a la que se había sujetado una tubería perforada que proyectaba agua en una cantidad aproximadamente de 2,4 l/min, ya que la separación entre los elementos de proyección extremos es de 0,60 m. Se separaron las boquillas $30 \mathrm{~cm}$ debido al tamaño de las probetas para proyectar el agua de manera más regular sobre las mismas. El ensayo finalizó a las 4 horas y 30 minutos de iniciado, cuando en las probetas que no se habían hidrofugado se apreciaba que llegaba el agua al trasdós.

El seguimiento del agua que pudiera penetrar en los muretes se realizó mediante dos procedimientos, además de comprobar que el agua llegaba al trasdós en alguna zona:

El primero consistió en colocar sondas de humedad para lo cual se realizaron perforaciones de $\varnothing 6 \mathrm{~mm}$ en la parte posterior de los muretes y se introdujeron una serie de sondas «saveris $\mathrm{H}_{4} \mathrm{D}$ » para medir el progreso de la humedad. Estas sondas se situaron en tendeles de argamasa e hiladas de ladrillo alternativamente, las sondas 1,3 y 5 están situadas en tendeles de argamasa, la sonda 1 es la colocada en el tendel que está debajo de la hilada inclinada, y las sondas 2, 4 y 6 están situadas en hiladas de ladrillo, la sonda 6 es la que está situada más alejada de la albardilla (Figura 3).

El segundo consistió en seguir visualmente el progreso del agua en las caras laterales de las probetas, protegidas por las planchas de policarbonato translúcidas, ya que al absorber agua tanto el ladrillo como la argamasa cambian a un tono más oscuro (Figuras 4 y 5). Entre la cara exterior de los muretes y las planchas de policarbonato y debido a la irregularidad de la fábrica se dejó una cámara de aire de pocos milímetros de espesor.

Una vez realizados los cuatro ensayos se dibujaron las gráficas con los datos de humedad medidos por las sondas situadas en la parte posterior para comparar los resultados de las cuatro probetas, así como se comparó el progreso del humedecimiento en el lateral de los muretes.

\subsubsection{Ensayo realizado al murete de ladrillo de tejar sin hidrofugar}

En este ensayo todas las sondas alcanzan el $100 \%$ de humedad a las tres horas de empezado el ensayo. La sonda 1 , la situada debajo de la albardilla, es la primera que mide el 


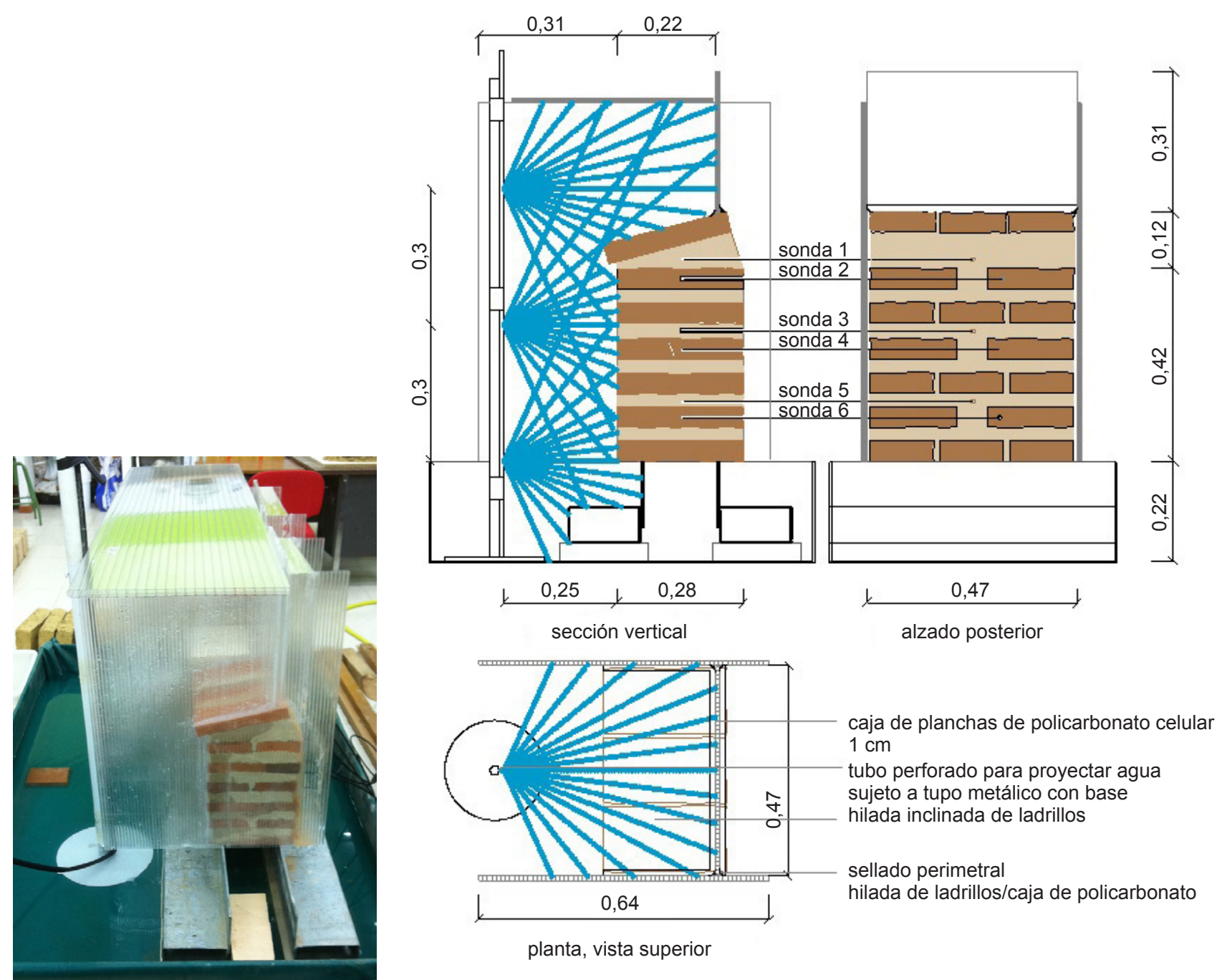

Figura 3. Fotografía de la realización del ensayo a la izquierda y dibujo del proceso de proyección de agua de una de las probetas de ladrillo de tejar.

$100 \%$ a los 110 minutos de iniciado el ensayo, la sonda 2 es la segunda que alcanza el $100 \%$ a los 150 minutos, la sonda 3 a los 190 minutos, la sonda 4 a los 170 minutos, la sonda 5 a los 180 minutos y la sonda 6 a los 190 minutos.

Visualmente se puede ver cómo el agua penetra por la albardilla de ladrillos al tiempo que lo hace por el frente de la probeta y se puede comprobar (Figura 4) que en la zona inferior del muro el agua penetra de forma más rápida que en la zona situada debajo del vuelo de la hilada de albardilla. Aunque la sonda 1 es la primera que mide una humedad del $100 \%$ la entrada de agua se produce de manera bastante uniforme por toda la zona donde se proyecta el agua excepto en las dos hiladas inferiores, en las que parece que penetra el agua más rápidamente, debido posiblemente a que el vuelo de la albardilla no protege la zona inferior y a que no hay goterón. Las imágenes de la Figura 4 reflejan el humedecimiento de la probeta por la cara lateral y están realizadas de izquierda a derecha: 12:40, 13:40, 14:10 y 14:40 (el ensayo se había empezado a las 09:30).

\subsubsection{Ensayo realizado al murete de ladrillo de tejar hidrofugado}

En este ensayo, como se puede observar en los gráficos de la Figura 6, no hay apenas variaciones en las medidas de humedad que miden las sondas, el agua, debido a la hidrofugación de la cara sobre la que se proyecta, no penetra en la probeta. Durante el ensayo hay una ligera variación de la humedad ambiente que tampoco incide en las medidas de las sondas situadas en la probeta. Ni en la cara lateral ni el trasdós se apreciaba visualmente el humedecimiento de la probeta.

\subsubsection{Ensayo realizado al murete de ladrillo moderno sin hidrofugar}

En este ensayo todas las sondas alcanzan el $100 \%$ de humedad de dos horas y media de empezado el ensayo, antes que en el ensayo de la probeta de ladrillo de tejar. La sonda 1 es la primera que mide el $100 \%$ a los 60 minutos de iniciado el ensayo, la sonda 2 es la última que alcanza el 100\% a los 150 minutos, la sonda 3 a los 100 minutos, la sonda 4 a los 150 minutos, la sonda 5 a los 100 minutos y la sonda 6 a los 60 minutos. No llegan a alcanzar el $100 \%$ de humedad en el orden en el que están situadas. Se produce un efecto similar a la de la probeta de ladrillo de tejar, en las hiladas inferiores el agua penetra con más facilidad que en las situadas debajo de las hiladas voladas de la albardilla y porque no hay goterón en la parte inferior del murete que vuela respecto de los perfiles en los que apoya, como ya se ha indicado. Las imágenes de la Figura 5 reflejan el humedecimiento de la probeta por la cara lateral y están realizadas de izquierda a derecha: 11:40, 12:10, 12:40 y 13:40 (el ensayo se había iniciado a las 09:30 horas). 

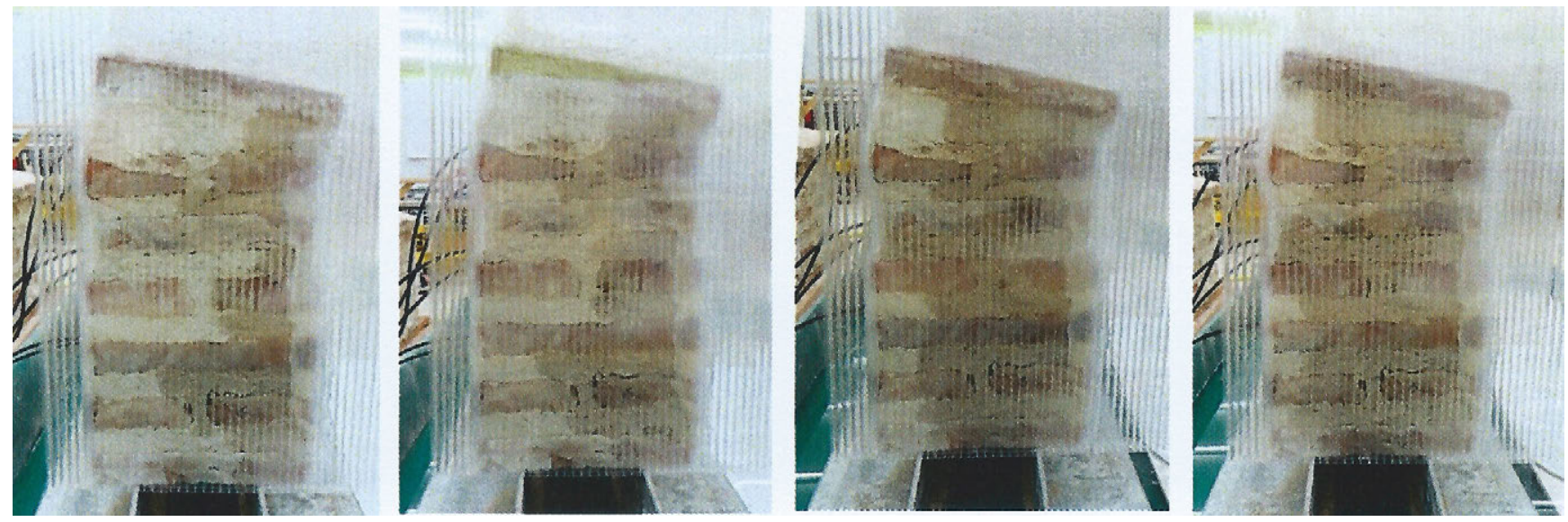

Figura 4. Fotografías del proceso de humedecimiento en el murete de ladrillo de tejar, sin hidrofugar.
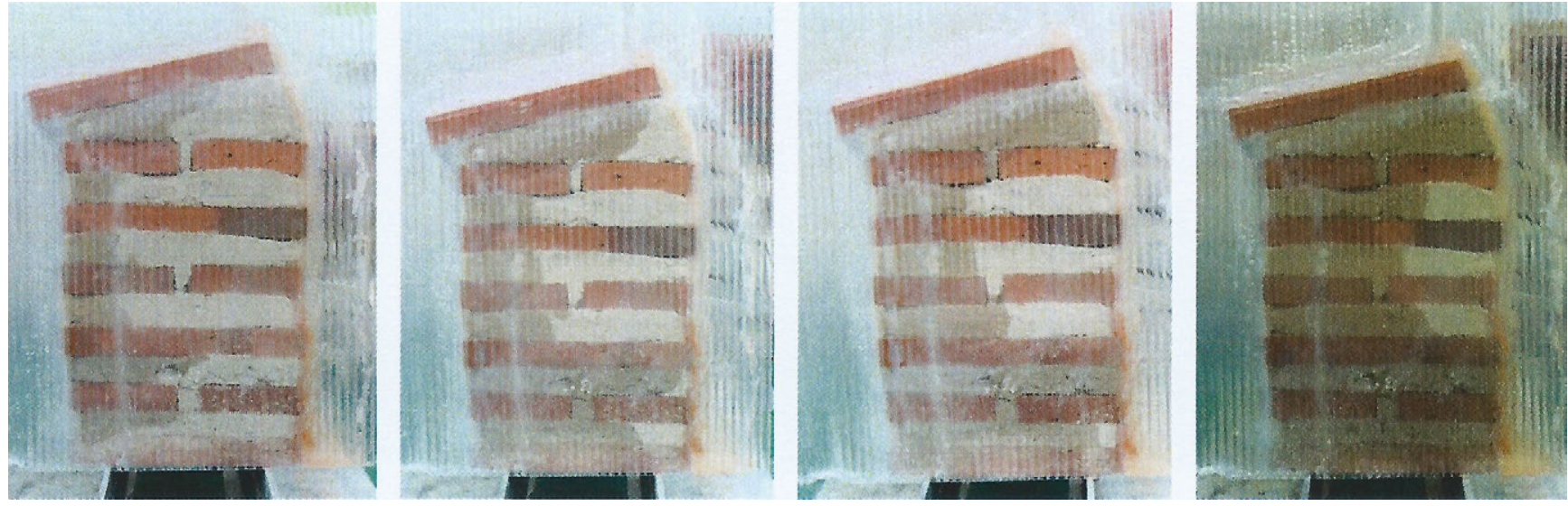

Figura 5. Progreso del humedecimiento en la probeta de ladrillo moderno sin hidrofugar.

2.1.4. Ensayo realizado al murete de ladrillo de moderno hidrofugado

En este ensayo, como se puede observar en las gráficas de la Figura 6, no hay apenas variaciones en las medidas de humedad que miden las sondas, el agua no penetra en la probeta debido a la hidrofugación de la cara sobre la que se proyecta. Durante el ensayo hay una ligera variación de la humedad ambiente que tampoco incide en las medidas de las sondas situadas en la probeta.

Las medidas de humedad de las sondas de los cuatro muretes se han representado en cuatro gráficas en la Figura 6 de manera que los resultados se puedan comparar mejor. Se puede comprobar que en las dos probetas hidrofugadas no hay variación en la medición de las sondas de humedad, porque no penetra el agua en los 270 minutos que dura el ensayo. Mientras que en las probetas no hidrofugadas sí que ha penetrado el agua, que es lo que indican las sondas de humedad situadas en las perforaciones realizadas por la parte posterior de las mismas y el humedecimiento de los ladrillos y la argamasa que se puede ver por los laterales de las probetas:

- En la probeta de ladrillo de tejar la sonda 1 empieza a medir el 100\% de humedad a los 110 minutos y las últimas son la 3 y la 6 a los 190 minutos. La razón por la que la sonda 3 llegue al $100 \%$ al tiempo que la 6 puede que sea que está en la zona donde el vuelo protege a la fachada y más alejada que la 1 y la 2 por la albardilla.
- En la probeta de ladrillo moderno la sonda 1 empieza a medir el $100 \%$ de humedad a los 60 minutos, y las sondas 2 y 4 son las que más tardan en medir el 100\% de humedad, a los 150 minutos. Estos datos coinciden con lo observado en las fotografías de la Figura 5, y la razón puede estar en que el vuelo protege a la fábrica de la entrada de agua.

Estos datos parecen indicar que la probeta ejecutada con ladrillo de tejar absorbe más lentamente el agua proyectada que la probeta de ladrillo moderno.

Los dos muretes absorben el agua tanto por la zona del albardilla como por el frente de la fachada y en ambas probetas hay una absorción de agua mayor a partir de la segunda hilada, empezando por abajo, posiblemente porque la zona situada debajo del vuelo del albardilla está protegida por el mismo y esta protección no es eficaz cuando llega a esta hilada.

\subsection{Ensayos realizados a los materiales: ladrillo y argamasa}

Al tiempo que se realizaban los ensayos en las probetas se hicieron otros ensayos a los ladrillos y a las probetas de argamasa para comprobar cómo afectaba el tratamiento a la succión y absorción de agua. Los ensayos se han seleccionado por entender que son los que pueden aportar mayor información sobre el proceso de absorción de agua. Estos ensayos se han realizado a los dos tipos de ladrillo: de tejar y moderno empleados para construir las probetas, y a probetas 

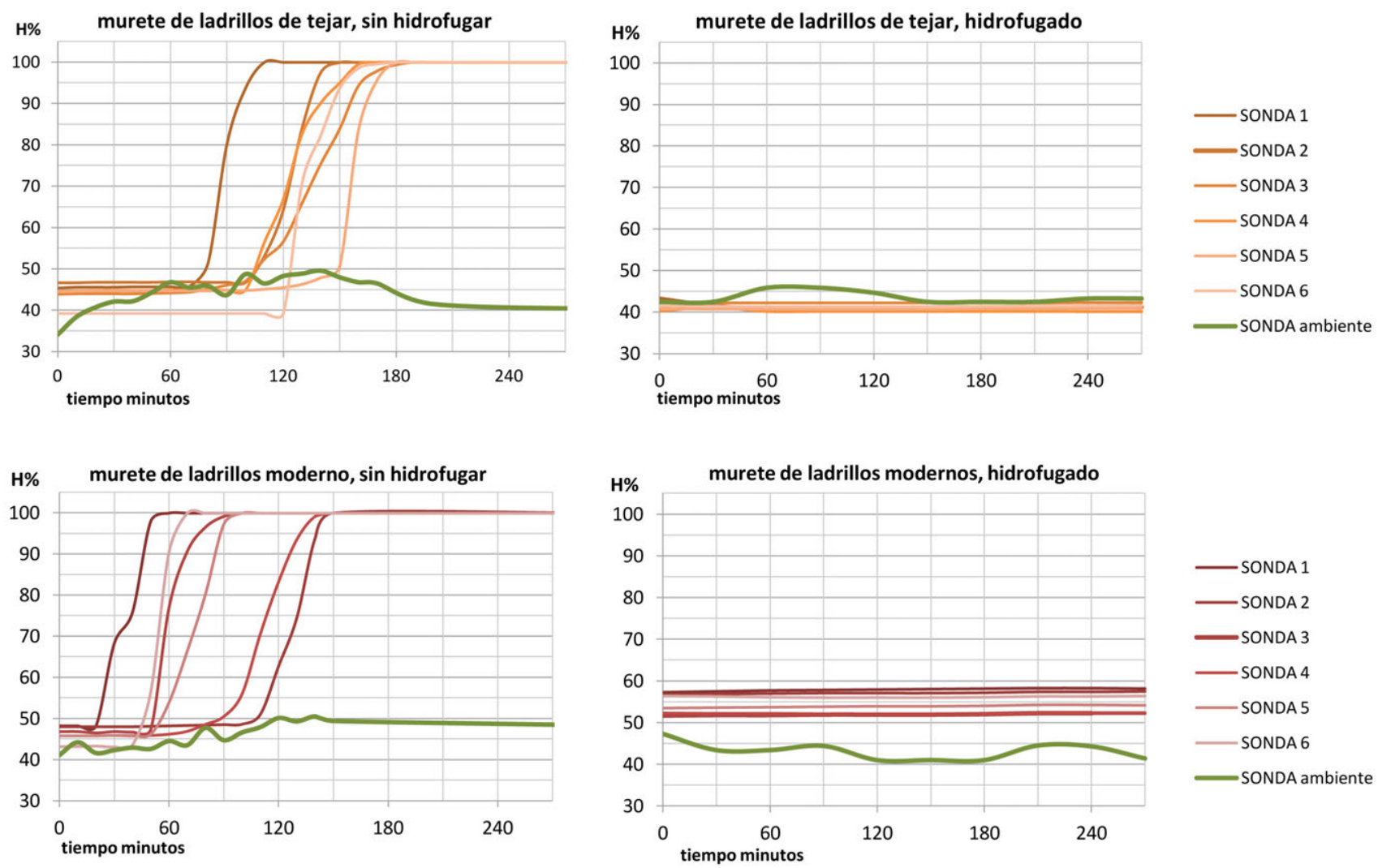

Figura 6. Gráficas humedad/tiempo de los datos de las seis sondas situadas en los cuatro muretes durante los ensayos de proyección de agua.

de argamasa de dosificación 1/3, de tamaño $4 \times 4 \times 16 \mathrm{~cm}$, sin hidrofugar y después de hidrofugarlos por inmersión durante 2 minutos en el hidrofugante a base de siloxanos, que se ha empleado para hidrofugar las probetas.

\subsubsection{Ensayos realizados según el procedimiento de UNE-EN 772-11}

Este ensayo, según la norma UNE-EN 772-11 (6) de determinación de absorción de agua por capilaridad, se ha seleccionado porque en el DB HS1 «protección frente a la humedad» del CTE para poder considerar que una hoja de fábrica es una barrera frente a la entrada del agua exterior se indica que el ladrillo cerámico debe tener una succión $\leq 4,5 \mathrm{~kg} / \mathrm{m}^{2} \times \min$. En este documento se refieren a esta característica del material como «higroscopicidad del material componente de la hoja principal» de una fachada.

El ensayo se realiza desecando los ladrillos y las probetas de argamasa hasta masa constante y sumergiendo en agua la tabla de las piezas, a una profundidad de $5 \mathrm{~mm} \pm 1 \mathrm{~mm}$ durante 1 minuto. Se pesan las piezas secas y después del minuto se calcula la tasa inicial de absorción de agua utilizando la siguiente fórmula:

$$
C_{w i, s}=\frac{m_{s o, s}-m_{s e c o, s}}{A_{s} t} \times 10^{3} \quad\left[\mathrm{~kg} / \mathrm{m}^{2} \times \mathrm{min}\right]
$$

Donde:

$C_{w i, s} \quad$ tasa inicial, en kilogramos por metro cuadrado minuto.

$m_{s o, s} \quad$ masa de la probeta después de la inmersión durante un tiempo $t$, en gramos (g).

$m_{\text {seco,s }}$ masa de la probeta después del secado, en gramos (g).

$A_{s} \quad$ seco,s $\quad$ superficie de la cara ladrillo sumergida en el agua en milímetros cuadrados $\left(\mathrm{mm}^{2}\right)$.

Los valores de absorción que se obtuvieron en los ensayos los que figuran en la Tabla 1 y en la Figura 7.

Para la argamasa se optó por realizar el ensayo siguiendo el procedimiento de la norma de ladrillo y no el de la norma UNE-EN 1015-18 «Métodos de ensayo de los morteros de albañilería. Parte 18 Determinación del coeficiente de absorción de agua por capilaridad del mortero endurecido», para poder comparar los resultados, ya que los procedimientos de ensayo de ambas normas son muy diferentes.

Tabla 1. Resultado de los ensayos según la norma UNE-EN 772-11.

\begin{tabular}{|c|c|c|c|c|c|c|}
\hline & \multicolumn{2}{|c|}{ Ladrillo de tejar } & \multicolumn{2}{c|}{ Ladrillo moderno } & \multicolumn{2}{c|}{ Argamasa } \\
\cline { 2 - 7 } & Sin hidrofugar & Hidrofugado & Sin hidrofugar & Hidrofugado & Sin hidrofugar & Hidrofugado \\
\hline$\left[\begin{array}{c}\boldsymbol{C}_{\text {wi,s }} \\
{\left[\mathrm{kg} /\left(\mathbf{m}^{2} \times \mathbf{m i n}\right)\right]}\end{array}\right.$ & 1,60 & 0,01 & 4,54 & 0,02 & 1,14 & 0,05 \\
\hline
\end{tabular}


2.2.2. Ensayos realizados según el procedimiento de la norma UNE-EN 771-21

La norma UNE-EN 771-21 (7), determinación de la absorción de agua por inmersión, se ha seleccionado por ser el valor de absorción de agua del que se informa en el marcado $\mathrm{CE}$ de ladrillos cerámicos. Para realizar el ensayo primero se secaron las probetas en horno a $\pm 105^{\circ} \mathrm{C}$ hasta masa constante, se pesaron, masa seca, y luego se sumergieron en un tanque de agua a temperatura ambiente durante 24 horas y se pesaron, masa húmeda. Se calcula la absorción de agua $W_{s}$ mediante la fórmula:

$$
W_{s}=\frac{M_{s}-M_{d}}{M_{d}} \times 100 \%
$$

Donde:

$M_{s}$ masa húmeda

$M_{d}^{s}$ masa seca

El ensayo de absorción en agua se ha realizado, como ya se ha indicado, a los ladrillos sin hidrofugar e hidrofugados y a probetas de argamasa. Los resultados están en la Tabla 2 y en la Figura 7.

Al comparar los resultados de los ensayos de las probetas no hidrofugadas, se puede comprobar que los tres materiales presentan valores muy diferentes según el ensayo. El ladrillo moderno es el que más agua absorbe en el ensayo para conocer la tasa inicial de absorción de agua, succión, y el ladrillo de tejar absorbe más cantidad de agua en el ensayo de inmersión en agua a temperatura ambiente. La argamasa es el material que absorbe menos agua en el ensayo para conocer la tasa inicial de absorción de agua, mientras que el ladrillo de tejar es el que menos cantidad de agua absorbe en el ensayo de absorción. La argamasa de cal y arena, una vez que ha fraguado, presenta una succión baja. Los morteros de cemento con los que se ejecutan los muros actualmente suelen presentar unos valores más elevados de succión que las piezas cerámicas y de hormigón, y se suele considerar que las juntas es el elemento por donde penetra con mayor facilidad el agua (8).

Los resultados del ensayo de la tasa inicial de absorción son, evidentemente, los que tienen mayor relación con los ensayos realizados a los muretes sin hidrofugar. El de ladrillo moderno es el que se humedece antes con un valor $C_{w i, s}=5,64 \mathrm{~kg} / \mathrm{m}^{2} \times \mathrm{min}$, mientras que el ladrillo de tejar tiene un valor $C_{w i, s}=1,60 \mathrm{~kg} / \mathrm{m}^{2} \times$ min, mucho menor y más parecido al de la argamasa $C_{w i, s}=1,14 \mathrm{~kg} / \mathrm{m}^{2} \times \min$.

\subsubsection{Ensayos realizados de manera similar al procedimiento de ensayo de permeabilidad de las tejas cerámicas}

Se realizó un tercer tipo de ensayo siguiendo el procedimiento para evaluar la permeabilidad de las tejas de arcilla cocida UNE-EN 539-1 (9), método de ensayo 2, en el que se determina el tiempo transcurrido hasta la caída de la primera gota, después de aplicar agua a la superficie de la teja por la cara expuesta al exterior. Este ensayo permite comprobar visualmente si el agua pasa a través de la pieza. La permeabilidad se ensayó colocando las probetas en posición horizontal, como si se tratara de una teja, entre varias planchas de metacrilato, sellando las juntas entre los materiales, se echó agua hasta una altura de $60 \mathrm{~mm}$ y se midió el tiempo hasta la caída de la primera gota (Figura 8).

Tabla 2. Resultado de los ensayos según la norma UNE-EN 771-21.

\begin{tabular}{|c|c|c|c|c|c|c|}
\hline & \multicolumn{2}{|c|}{ Ladrillo de tejar } & \multicolumn{2}{c|}{ Ladrillo moderno } & \multicolumn{2}{c|}{ Probeta argamasa } \\
\cline { 2 - 7 } & Sin hidrofugar & Hidrofugado & Sin hidrofugar & Hidrofugado & Sin hidrofugar & Hidrofugada \\
\hline \multirow{2}{*}{$\boldsymbol{W}_{\boldsymbol{s}} \mathbf{( \% )}$} & 17,20 & 7,50 & 8,17 & 0,14 & 9,25 & 0,75 \\
\hline
\end{tabular}
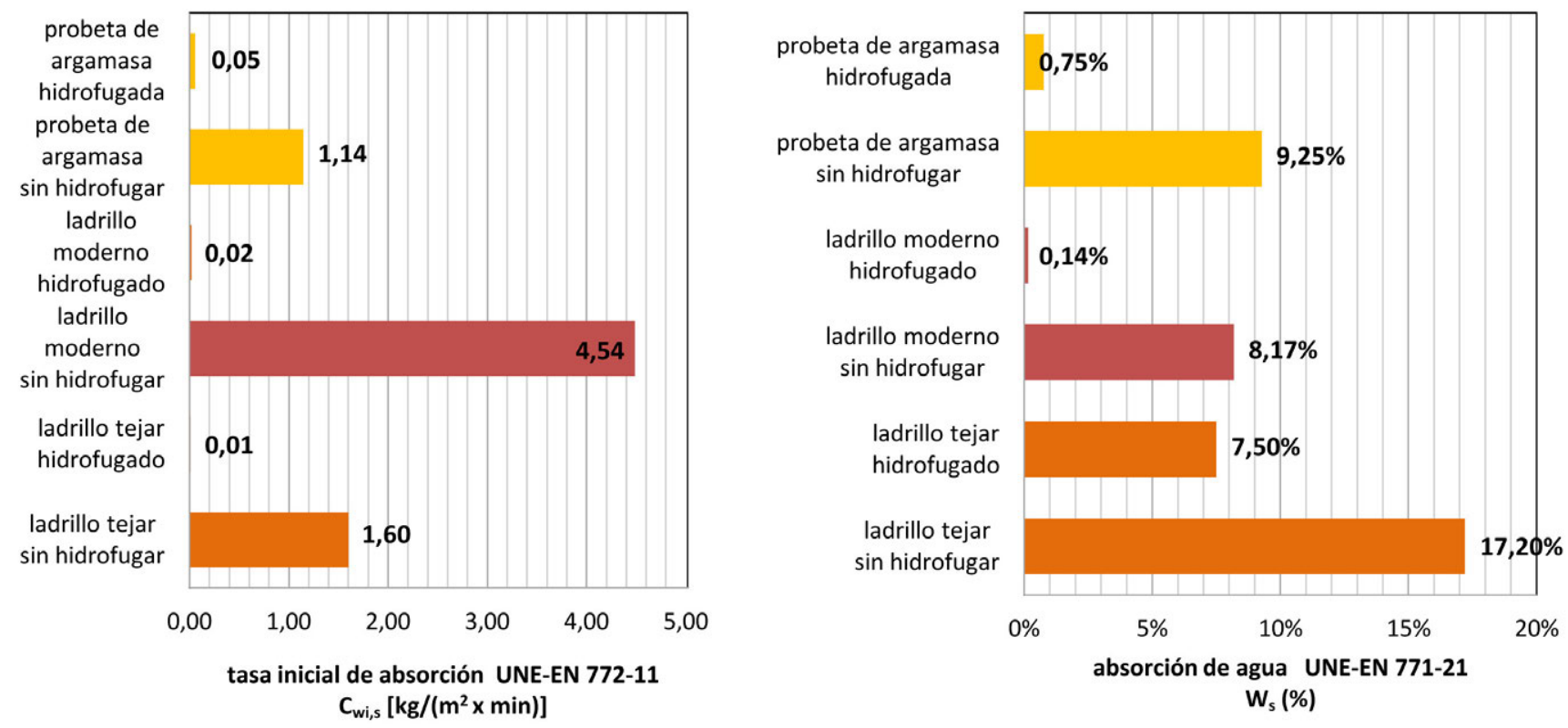

Figura 7. Resultados del ensayo de la norma UNE EN 772-11 a la izquierda, y según la norma UNE-EN 771-21 a la derecha. 


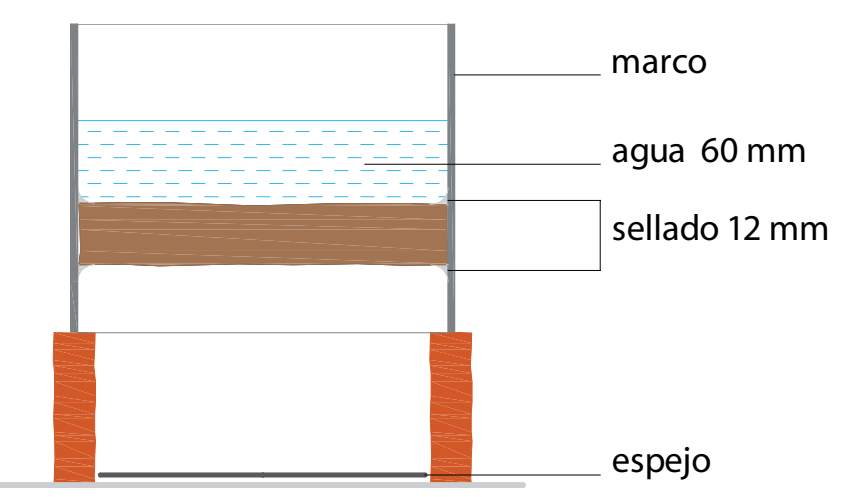

Figura 8. Dibujo y fotografía del ensayo según la UNE-EN 539-1 de permeabilidad para las tejas de arcilla cocida realizado a un ladrillo de tejar.
Este ensayo se ha realizado a los dos tipos de ladrillo y a probetas de argamasa ejecutadas con el formato de los ladrillos, por si las dimensiones, en especial el espesor de las probetas, fuese significativo en el resultado final. En la Tabla 3 están los resultados de un ensayo que se paró a los 21 días.

Como se puede comprobar por los resultados las probetas de argamasa, de diferentes tamaños, hidrofugadas y sin hidrofugar, a los 21 días no han goteado. Una vez ejecutadas se esperó a que fraguarán y endurecieran 90 días.

\section{CONCLUSIONES}

La conclusión primera y más evidente es que el producto hidrofugante es altamente eficaz, ya que ha evitado o ralentizado la absorción de agua tanto en los muretes de fábrica como en los ladrillos y las probetas de argamasa. Los más significativos son los ensayos según las normas UNE-EN 772-11 en el que apenas hay absorción de agua y el realizado según la norma UNE-EN 539-1 en el que a los 21 días el agua no ha atravesado las probeta y no ha caído ninguna gota de agua.

Si se analizan los resultados de los ensayos de los materiales, la información que proporcionan frente a la absorción de agua es bastante diferente. Si bien, el que ofrece valores más próximos al resultado de los ensayos de los muretes de fábrica es el de la norma UNE-EN 772-11, que sirve para conocer la tasa inicial de absorción, ya que es el ensayo en el que el ladrillo moderno absorbe agua más rápidamente. En el DB HS1 «protección frente a la humedad» del CTE se establece que para que una hoja de fábrica pueda ser barrera frente a la entrada del agua de lluvia la succión debe ser $<4,5 \mathrm{~kg} / \mathrm{m}^{2} \times \mathrm{min}$. El ladrillo de tejar presenta un valor

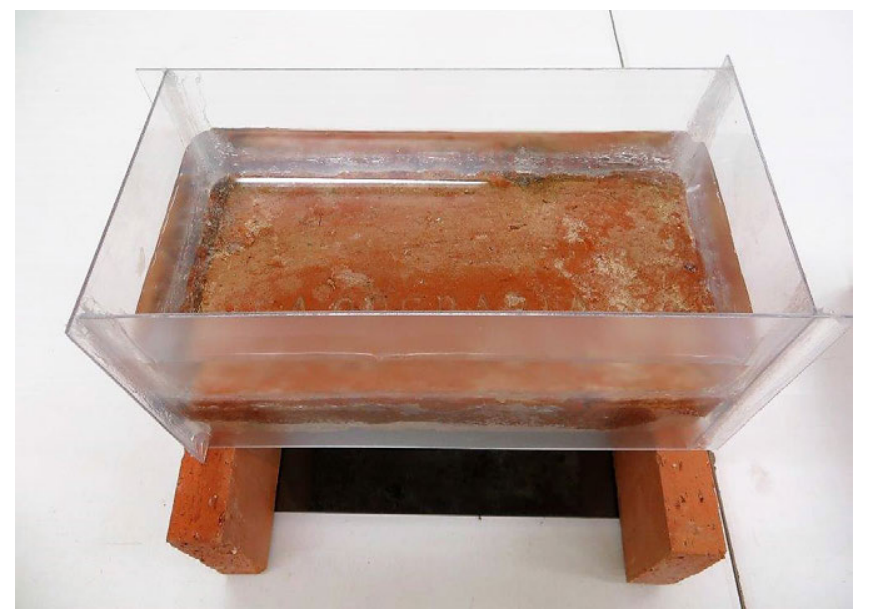

de succión $<4,5 \mathrm{~kg} / \mathrm{m}^{2} \times$ min mientras que el moderno es $>4,5 \mathrm{~kg} / \mathrm{m}^{2} \times \min$, y en la fábrica de ladrillo de tejar, sin hidrofugar, el proceso de entrada de agua es más lento.

De los ensayos realizados a los ladrillos sin el tratamiento hidrofugante los realizados según las normas UNE-EN 77121 y la UNE-EN 539-1 el ladrillo de tejar es el que absorbe más agua y con mayor rapidez, porque la pieza está sumergida en agua y los poros y capilares de los ladrillos de tejar son de mayor dimensión.

El vuelo de las albardillas protege la fábrica situada inmediatamente debajo, ya que en esta zona es absorbida el agua con mayor lentitud. La disposición de la albardilla, con una pendiente de $10^{\circ}$, parece que tendría que ser la zona donde el agua proyectada penetrase más rápidamente, pero el agua penetra por todo el frente de la probeta de manera similar, si bien la primera probeta que mide el $100 \%$ de humedad es la situada debajo de la albardilla. La pendiente de $10^{\circ}$ es la fijada en el DB HS1 «protección frente a la humedad» del CTE como mínima para un alfeizar y a tenor de los resultados, de manera acertada.

\section{AGRADECIMIENTOS}

Los ensayos se han realizado con la ayuda concedida por el Ministerio de Economía y Competitividad de España al Proyecto de Investigación titulado «Protección frente a la humedad de las fábricas antiguas de ladrillo al descubierto. Estudio del empleo de hidrofugantes en su restauración» BIA2010-19245 en el Laboratorio de Construcción de la Escuela Técnica Superior de Arquitectura de la Universidad de Valladolid.

Tabla 3. Resultado de los ensayos según la norma UNE-EN 539-1.

\begin{tabular}{|c|c|c|c|c|c|c|c|c|}
\hline & \multirow{2}{*}{\multicolumn{2}{|c|}{$\begin{array}{l}\text { Ladrillo de tejar } \\
28 \times 14 \times 5 \mathrm{~cm}\end{array}$}} & \multirow{2}{*}{\multicolumn{2}{|c|}{$\begin{array}{c}\text { Ladrillo moderno } \\
23,5 \times 11 \times 3 \mathrm{~cm}\end{array}$}} & \multicolumn{4}{|c|}{ Probetas de argamasa } \\
\hline & & & & & \multicolumn{2}{|c|}{$28 \times 14 \times 5 \mathrm{~cm}$} & \multicolumn{2}{|c|}{$23,5 \times 11 \times 3 \mathrm{~cm}$} \\
\hline & \begin{tabular}{c|} 
Sin \\
hidrofugar
\end{tabular} & Hidrofugado & $\begin{array}{l}\text { Sin } \\
\text { hidrofugar }\end{array}$ & Hidrofugado & $\begin{array}{c}\text { Sin } \\
\text { hidrofugar }\end{array}$ & Hidrofugado & $\begin{array}{c}\text { Sin } \\
\text { hidrofugar }\end{array}$ & Hidrofugado \\
\hline $\begin{array}{l}\text { Tiempo } \\
\text { trascurrido } \\
\text { hasta que } \\
\text { gotea }\end{array}$ & $205 \mathrm{~min}$ & $\begin{array}{l}\text { A los } 21 \text { días } \\
\text { no gotea ni } \\
\text { aparecen } \\
\text { machas de } \\
\text { agua en el } \\
\text { trasdós }\end{array}$ & $540 \mathrm{~min}$ & $\begin{array}{l}\text { A los } 21 \text { días } \\
\text { no gotea ni } \\
\text { aparecen } \\
\text { manchas de } \\
\text { agua en el } \\
\text { trasdós }\end{array}$ & \multicolumn{4}{|c|}{$\begin{array}{l}\text { A los } 21 \text { días no gotea ni aparecen manchas de agua en el } \\
\text { trasdós }\end{array}$} \\
\hline
\end{tabular}




\section{REFERENCIAS}

(1) Cortes Generales (2006). Real Decreto 314/2006 por el que se aprueba el Código Técnico de la Edificación. Boletín Oficial del Estado, n. ${ }^{\circ}$ 74. España.

(2) Cultrone, G., de la Torre, M., Sebastián, E., Cazalla, O. (2003). Evaluación de la durabilidad de los ladrillos mediante técnicas destructivas (TD) y no-destructivas (TND). Materiales de Construcción, 53(269): 41-60, doi: http://dx.doi. org/10.3989/mc.2003.v53.i269.267.

(3) AENOR-CEN (2003). UNE-EN 771-11 Especificaciones de piezas para fábrica de albañilería. Parte 1: Piezas de arcilla cocida. Asociación Española de Normalización (AENOR).

(4) Coronado Martín, J., García Santos, A., Padial Molina, J. (2013). La influencia de los productos hidrofugantes en la succión del ladrillo cerámico cara vista. Boletín de la Sociedad Española de Cerámica y Vidrio, 52(4): XV-XVIII, doi: http://dx.doi.org/10.3989/cyv.2013.v52.i4.1221.

(5) Moira, A., Wilson, W. D., Hoff, C. H. (1995). Water movement in Poros Building Materials-XIV. Adsorption into a Twolayer composite $\left(\mathrm{S}_{\mathrm{A}}\right.$ less than $\left.\mathrm{S}_{\mathrm{B}}\right)$. Building and Environment, 30(2): 221-227.

(6) AENOR-CEN (2001). UNE-EN 772-11 Métodos de ensayo de piezas para fábrica de albañilería. Parte 11: Determinación de la absorción de agua por capilaridad de piezas para fábrica de albañilería, en hormigón, piedra natural y artificial, y de la tasa de absorción de agua inicial de las piezas de arcilla cocida para fábrica de albañilería. Asociación Española de Normalización (AENOR).

(7) AENOR-CEN (2011). UNE-EN 771-21 Métodos de ensayo de piezas para fábrica de albañilería. Parte 21: determinación de la absorción de agua de piezas para fábrica de albañilería de arcilla cocida y silicocalcáreas por absorción de agua fría. Asociación Española de Normalización (AENOR).

(8) Piaia, J. C. Z., Cheriaf, M., Rocaha, J., Mustelier, N. (2013). Measurements of water penetration and leakage in masonry wall: Experimental results and numerical simulation. Building and Environment, 61: 18-26, doi: http://dx.doi. org/10.1016/j.buildenv.2012.11.017.

(9) AENOR-CEN (2007). UNE-EN 539-1 Tejas de arcilla cocida para colocación discontinua. Determinación de las características físicas. Parte 1: ensayo de permeabilidad. Asociación Española de Normalización (AENOR). 